\title{
TỬ QUAN ĐIỂM CỦA ĐẢNG CỘNG SẢN VIỆT NAM ĐẾN THỰC TIẼ̃N XÂY DỬNG AN SINH XÃ HỘI Ở ĐÀ NÃNG HIỆN NAY
}

\author{
Lê Đức Thọ ${ }^{{ }^{*}}$ \\ ${ }^{a}$ Khoa Co bản, Truờng Cao đẳng nghề Đà Nẵng, Đà Nã̃ng, Việt Nam \\ Lịch sử bài báo \\ Nhận ngày 24 tháng 08 năm 2017 \\ Chỉnh sửa ngày 03 tháng 10 năm 2017 | Chấp nhận đăng ngày 09 tháng 10 năm 2017
}

\section{Tóm tắt}

Bảo đảm an sinh xã hội (ASXH) trở thành vấn đề trung tâm trong chiến lược phát triển đất nuớc, bởi vì việc chăm lo, không ngùng nâng cao đời sống vật chất và tinh thần của nhân dân là muc tiêu cao nhất của sư nghiệp xây dụng xã hội Xã hội chủ nghĩa ở Việt Nam. Và hiện nay, chúng ta đang phấn đấu đến năm 2020 hệ thống ASXH sẽ bao phủ khắp toàn dân. Trong bài viết này, tác giả phân tích các quan điểm của Đảng Công sản Việt Nam về thực hiện ASXH trong giai đoạn hiện nay; Phân tích thục trạng của vấn đề ASXH ở Đà Nã̃ng và qua đó, định hướng một số giải pháp nhằm nâng cao vấn đề ASXH cho người dân ở thành phố Đà Nẵng hiện nay.

Từ khóa: An sinh xã hội; Bảo đảm an sinh xã hội; Đà Nẵng.

\section{GIỚI THIỆU}

Thực hiện chương trình "Thành phố 4 an”, Đà Nẵng đã đẩy mạnh công tác ASXH nhằm nâng cao đời sống vật chất và tinh thần của nhân dân, tạo sự phát triển đồng bộ và hài hòa để thực hiện các mục tiêu phát triển kinh tế - xã hội, quốc phòng - an ninh trên địa bàn. Trong những năm qua, vấn đề ASXH đã được Thành phố quan tâm xây dựng và đã đạt những thành quả đáng ghi nhận, tuy nhiên, vẫn còn nhiều hạn chế, bất cập. Việc khảo sát một cách khách quan thực trạng thực thi chính sách ASXH ở thành phố Đà Nẵng hiện nay, trên cơ sở đó, đưa ra những luận cứ khoa học nhằm thực thi chính sách ASXH một cách có hiệu quả hơn là rất cần thiết. 


\section{CƠ SỞ VÀ PHƯƠNG PHÁP NGHIÊN CÚU}

\subsection{Cơ sở lý luận và thực tiễn}

Cơ sở lý luận: Dựa trên cơ sở lý luận của chủ nghĩa Mác - Lênin, tư tưởng Hồ Chí Minh, đường lối, chủ trương, chính sách của Đảng và Nhà nước ta về chính trị nói chung và vấn đề chính sách xã hội nói riêng.

Cơ sở thực tiễn: Quá trình lãnh đạo, chỉ đạo, thực hiện của Đảng bộ, chính quyền thành phố Đà Nẵng trong việc xây dựng và phát triển thành phố Đà Nẵng trên quan điểm phát triển bền vững của Đảng bộ Đà Nẵng (2015) về kết hợp phát triển kinh tế với thực hiện tiến bộ và công bằng xã hội, bảo vệ môi trường và tài nguyên thiên nhiên, nâng cao chất lượng cuộc sống, giải quyết tốt các vấn đề ASXH.

\subsection{Phương pháp nghiên cứu}

Kết hợp phương pháp nghiên cứu tài liệu, phương pháp phân tích thực chứng, phân tích chuẩn tắc, phương pháp so sánh, tổng hợp và khái quát hóa.

\section{KẾT QUẢ VÀ THẢo LUẬN}

\subsection{Khái niệm và bản chất của $\mathrm{ASXH}$}

\subsubsection{Khái niệm ASXH}

ASXH là một trong những vấn đề quan trọng mang tính chất phát triển hài hòa, bền vững, đồng thời là vấn đề mang tính chất cấp bách cho sự ổn định chính trị của mỗi quốc gia, khu vực. Nghiên cứu về ASXH vì thế cũng thu hút được một lượng lớn các học giả, các nhà khoa học quan tâm nghiên cứu khá lâu. Tuy nhiên, trong phát triển kinh tế thị trường, quá trình hội nhập kinh tế thế giới và những biến động về chính trị - xã hội của các khu vực, việc nghiên cứu đảm bảo ASXH trong điều kiện mới, cụ thể được các nhà khoa học trên thế giới đề cập và quan tâm nghiên cứu thời gian gần đây, trong đó đặc biệt là các nước như Mỹ, Anh, Cộng hòa Liên bang Đức, Thụy Điển, Nhật Bản và một số nước đang phát triển khác. Trong các viện nghiên cứu, các trường đại học ở các nước, 
vấn đề ASXH đã được xuất bản thành nhiều giáo trình, nhiều sách chuyên khảo, nhiều bài báo công bố trên các tạp chí chuyên ngành.

ASXH là một hệ thống các chính sách và giải pháp nhằm vừa bảo vệ mức sống tối thiểu của người dân trước những rủi ro và tác động bất thường về kinh tế, xã hội và môi trường, vừa không ngừng nâng cao đời sóng vật chất và tinh thần cho nhân dân. Bảo đảm ASXH và nâng cao phúc lợi xã hội không chỉ là bảo vệ quyền của mọi người dân theo Tuyên ngôn quốc tế nhân quyền của Liên hợp quốc, mà còn là nhiệm vụ quan trọng của mỗi quốc gia trong quá trình phát triển (Phùng, Nguyễn, \& Nguyễn, 2016).

\subsubsection{Bản chất của ASXH}

Về bản chất, ASXH góp phần đảm bảo thu nhập và đời sống cho người dân trong xã hội thông qua các biện pháp công cộng. Mục đích tạo ra sự "an sinh" (sống bình an) cho mọi thành viên trong xã hội. Do đó, ASXH mang tính xã hội và tính nhân văn sâu sắc.

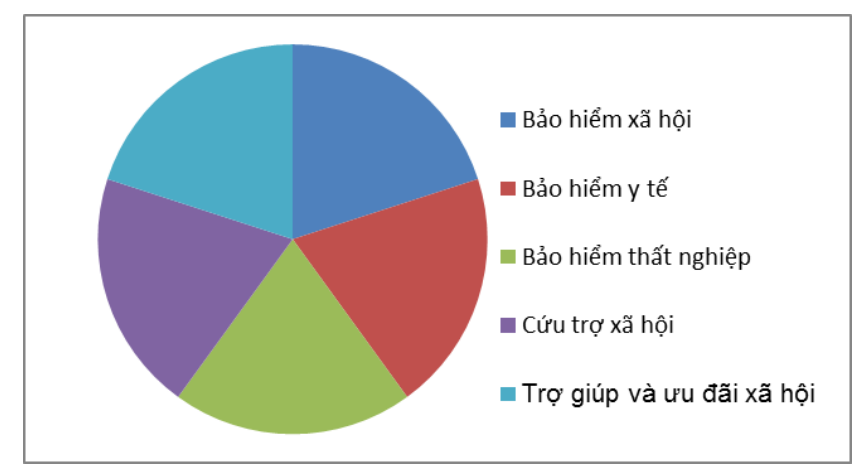

Hình 1. Cơ cấu hệ thống ASXH ở Việt Nam

Nguồn: Phùng, Nguyễn, và Nguyễn (2016)

Ở Việt Nam, cấu trúc của hệ thống ASXH gồm năm trụ cột như được mô tả trong Hình 1: 1) Bảo hiểm xã hội; 2) Bảo hiểm y tế; 3) Bảo hiểm thất nghiệp; 4) Cứu trợ xã hội; và 5) Trợ giúp và ưu đãi xã hội. Xét về thực chất, năm trụ cột này là nhằm thực hiện ba chức năng chiến lược của hệ thống ASXH: Phòng ngừa rủi ro; Giảm thiểu rủi ro; và Khắc phục rủi ro. So với mô hình phổ biến trên thế giới, hệ thống ASXH ở nước ta có một cấu phần đặc thù, đó là chính sách ưu đãi xã hội. Chính sách này nhằm thực hiện mục tiêu cao cả là đền ơn, đáp nghĩa đối với sự hy sinh, công lao đặc biệt và cống hiến to lớn của 
những người có công với cách mạng, với đất nước; Thực hiện trách nhiệm của Nhà nước, của xã hội chăm lo, bảo đảm cho người có công có cuộc sống ổn định và ngày càng được cải thiện.

\subsection{Quan điểm của Đảng Cộng sản Việt Nam về $\mathrm{ASXH}$}

Ở Việt Nam, ASXH trở thành một trong những trụ cột cơ bản trong hệ thống các chính sách xã hội được Đảng và Nhà nước ta quan tâm xây dựng. ASXH là nhân tố đảm bảo công bằng xã hội. Thực tiễn phát triển đã cho thấy ASXH có vai trò rất lớn trong việc khắc phục những hệ lụy của phân hóa xã hội, tăng cường gắn kết xã hội, sự đồng thuận và đảm bảo ổn định chính trị. Tuy nhiên, hệ thống ASXH của Việt Nam hiện nay chưa phát triển tương xứng với đà phát triển của xã hội, và so với đổi mới tư duy về mô hình kinh tế, việc đổi mới tư duy về mô hình đảm bảo ASXH và giải quyết các vấn đề xã hội nảy sinh còn chậm và thiếu bền vững. Trước yêu cầu nói trên, nghiên cứu xây dựng mô hình và định hướng chính sách ASXH ở Việt Nam là hết sức cấp thiết, phù hợp với mục tiêu và định hướng phát triển bền vững, tiến tới việc hoàn thiện mô hình đảm bảo ASXH ở nước ta trong những điều kiện và thách thức mới của bối cảnh quốc tế.

Trong quá trình đổi mới, Đảng Cộng sản Việt Nam cũng đã từng bước nhận thức và tìm được những biện pháp, bước đi để xử lý biện chứng mối quan hệ giữa phát triển kinh tế với việc thực hiện chính sách xã hội (bảo đảm công bằng xã hội, ASXH, tiến bộ xã hội). Từ Đại hội VI (1986) đến Đại hội VIII (1996), Đảng ta đã chính thức khẳng định một số quan điểm chỉ đạo tăng trưởng kinh tế phải gắn liền với tiến bộ và công bằng xã hội ngay trong từng bước và trong suốt quá trình phát triển (Đảng Cộng sản Việt Nam, 1996). Đến Đại hội IX của Đảng, chủ trương này trở thành một định hướng chiến lược để phát triển bền vững đất nước: “Tăng trưởng kinh tế đi liền với phát triển văn hoá, từng bước cải thiện đời sống vật chất và tinh thần của nhân dân, thực hiện tiến bộ và công bằng xã hội, bảo vệ và cải thiện môi trường ... Khẩn trương mở rộng hệ thống Bảo hiểm xã hội và ASXH...” (Đảng Cộng sản Việt Nam, 2001, tr. 97). Đến Đại hội X, Đảng ta tiếp tục khẳng định: "Kết hợp giữa các mục tiêu kinh tế với các mục tiêu xã hội trong phạm vi cả nước và từng địa phương; Thực hiện tiến bộ và công bằng xã hội ngay trong từng bước và từng chính sách phát triển kinh tế....” (Đảng Cộng sản Việt Nam, 2006, tr. 153). 
Lần đầu tiên trong Văn kiện Đại hội XI của Đảng Cộng sản Việt Nam, "bảo đảm ASXH" được khẳng định với tư cách là nội dung cấu thành của một trong 11 chủ đề chính của Báo cáo chính trị, và “phát triển hệ thống $\mathrm{ASXH}$ đa dạng, ngày càng mở rộng và hiệu quả” (Đảng Cộng sản Việt Nam, 2011, tr. 160) cũng được xem là một trong những nội dung hợp thành của sự định hướng về “Phát triển toàn diện các lĩnh vực văn hóa, xã hội hài hòa với phát triển kinh tế” trong Chiến lược phát triển kinh tế - xã hội giai đoạn 2011 2020. Đặc biệt, tại Hội nghị lần thứ 5 Ban chấp hành Trung ương Khóa XI, Đảng ta đã ban hành Nghị quyết "Một số vấn đề về chính sách xã hội giai đoạn 2012 - 2020”. Nghị quyết nhấn mạnh: Không ngừng cải thiện, nâng cao đời sống vật chất và tinh thần của người có công và bảo đảm $\mathrm{ASXH}$ là nhiệm vụ thường xuyên, quan trọng của Đảng, Nhà nước, của cả hệ thống chính trị và toàn xã hội. Ngày 22/11/2012, Bộ Chính trị đã ban hành Nghị quyết số 21-NQ/TW về tăng cường sự lãnh đạo của Đảng đối với công tác bảo hiểm xã hội, bảo hiểm y tế giai đoạn 2012 - 2020. Nghị quyết đã chỉ rõ mục tiêu cần phấn đấu là: Thực hiện có hiệu quả các chính sách, chế độ bảo hiểm xã hội, bảo hiểm y tế; Tăng nhanh diện bao phủ đối tượng tham gia bảo hiểm xã hội, nhất là bảo hiểm xã hội tự nguyện; Thực hiện mục tiêu bảo hiểm y tế toàn dân. Phấn đấu đến năm 2020, có khoảng $50 \%$ lực lượng lao động tham gia bảo hiểm xã hội, $35 \%$ lực lượng lao động tham gia bảo hiểm thất nghiệp, trên $80 \%$ dân số tham gia bảo hiểm y tế.

Chính sách xã hội đúng đắn, công bằng vì con người là động lực mạnh mẽ phát huy mọi năng lực sáng tạo của nhân dân trong sự nghiệp xây dựng và bảo vệ Tổ quốc. Từ nhiều năm qua, Đảng và Nhà nước ta luôn quan tâm xây dựng và tổ chức thực hiện các chính sách xã hội, coi đây vừa là mục tiêu, vừa là động lực để phát triển bền vững, ổn định chính trị xã hội, thể hiện bản chất tốt đẹp của chế độ ta. Nghị quyết Đại hội XII cũng chỉ rõ: Quản lý tốt sự phát triển xã hội; Bảo đảm ASXH, nâng cao phúc lợi xã hội; Thực hiện tốt chính sách với người có công; Nâng cao chất lượng chăm sóc sức khỏe nhân dân, chất lượng cuộc sống của nhân dân; Thực hiện tốt chính sách lao động, việc làm, thu nhập (Đảng Cộng sản Việt Nam, 2016).

Đại hội XII của Đảng ta đã nêu rõ phương hướng và nhiệm vụ ASXH là: Tiếp tục hoàn thiện chính sách $\mathrm{ASXH}$ phù hợp với quá trình phát triển kinh tế - xã hội; Mở rộng đối tượng và nâng cao hiệu quả của hệ thống ASXH đến mọi người dân; Tạo điều kiện 
để trợ giúp có hiệu quả cho tầng lớp yếu thế, dễ tổn thương hoặc những người gặp rủi ro trong cuộc sống (Đảng Cộng sản Việt Nam, 2016).

\subsection{Vấn đề ASXH ở Đà Nẵng hiện nay}

\subsubsection{Nhũng thành tưu đạt được về ASXH}

Đà Nẵng là thành phố thuộc trung ương, nằm trong vùng Nam Trung Bộ, Việt Nam. Đây là trung tâm kinh tế, văn hoá, giáo dục, khoa học và công nghệ lớn của khu vực miền Trung - Tây Nguyên, đang trong quá trình tiến hành đẩy mạnh công nghiệp hóa, hiện đại hóa $(\mathrm{CNH}, \mathrm{HĐH})$, đô thị hóa, mở rộng địa giới hành chính. Đà Nẵng luôn là đầu tàu trong phát triển kinh tế - xã hội và là “điểm sáng” trong giải quyết các vấn đề về ASXH ở miền Trung - Tây Nguyên. Tuy nhiên, đánh giá khách quan phải thấy, việc đảm bảo ASXH cho người dân còn khá nhiều hạn chế.

Đối với thành phố Đà Nẵng, Nghị quyết 33 của Bộ Chính trị (khóa IX), ngày 16/10/2003 về xây dựng và phát triển thành phố Đà Nẵng trong thời kỳ công nghiệp hóa, hiện đại hóa đất nước, đã xác định: Xâydựng thành phố Đà Nẵng trở thành một trong những đô thị lớn của cả nước, là trung tâm kinh tế - xã hội lớn của miền Trung. Trên cơ sở mục tiêu chung đó, thành phố Đà Nẵng đã thực hiện chủ trương gắn phát triển kinh tế với giải quyết các vấn đề xã hội, chính sách $\mathrm{ASXH}$, quan tâm nhân tố con người và đã đạt được những kết quả tích cực như sau:

- Trên lĩnh vục kinh tế: Tốc độ tăng trưởng kinh tế bình quân của Đà Nẵng từ 1997 - 2015 đạt 10.62\%, nhất là giai đoạn 2001 - 2010 đạt gần 11.96\%/năm (tỷ lệ này cao hơn nhiều so với bình quân cả nước là 7.07\%/năm). Đời sống của nhân dân không ngừng được nâng lên, thu nhập bình quân đầu người của năm 2011 đạt 23.62 triệu/người (tăng hơn 5 lần so với năm 1997 là 4,69 triệu/người) (Ban chỉ đạo Chương trình Mục tiêu giảm nghèo, 2015). Tăng trưởng kinh tế có tầm quan trọng hàng đầu, không chỉ để sớm đưa Đà Nẵng trở thành một thành phố hiện đại, phát triển, mà còn làm tiền đề để thực hiện nhiều mục tiêu xã hội.

- Trên lĩnh vục xã hội: Tiến bộ và công bằng xã hội luôn được chú trọng trong 
mối quan hệ với phát triển kinh tế, nhiều chính sách ASXH đậm tính nhân văn được triển khai thực hiện và đạt kết quả tốt. Chương trình thành phố "5 không" "3 có" gắn với công tác đảm bảo ASXH được thực hiện tốt: Trong 3 năm 2011 - 2013, với chủ đề "Năm ASXH”, thành phố tập trung chăm lo đời sống cho các đối tượng chính sách, đối tượng xã hội, hộ nghèo.

Mục tiêu "Không có hộ đặc biệt nghèo" cơ bản hoàn thành, Đề án giảm nghèo giai đoạn 2009 - 2015 về đích trước 3 năm (năm 2012), giai đoạn 2013 - 2017 về đích trước 2 năm (năm 2015), đến cuối năm 2015 không còn hộ nghèo theo chuẩn mới của Thành phố. Đề án "Có nhà ở” được triển khai đồng bộ bằng cả nguồn vốn ngân sách và xã hội hoá (Đã đưa vào sử dụng 176 khối nhà chung cư với gần 9.000 căn hộ; Đang triển khai xây dựng 128 khối chung cư với gần 17.500 căn hộ; Hoàn thành 02 khu ký túc xá sinh viên tập trung phía Tây và phía Đông thành phố, đáp ứng nhu cầu chỗ ở cho 5.500 sinh viên). Đặc biệt, tính đến cuối năm sẽ thoát hết hộ nghèo theo chuẩn của Thành phố, đạt $100 \%$ kế hoạch. Bên cạnh đó, hoàn thành vận động Quỹ Đền ơn đáp nghĩa (cấp thành phố) được 6.9/7.023 tỷ đồng, dự kiến đến tháng 12/2015 đạt 100\% kế hoạch.

Đề án "Có việc làm" được quan tâm thực hiện, tổ chức tốt các phiên giao dịch việc làm, kết nối cung cầu lao động, hằng năm giải quyết việc làm cho 3.2 vạn lao động; tỷ lệ lao động qua đào tạo ước đạt 55\%. Tỷ lệ thất nghiệp khu vực thành thị đến cuối năm 2015 giảm còn 4.15\% (cuối năm 2010 là 4.9\%) (Đảng bộ Đà Nẵng, 2015). Theo đó, tính đến thời điểm này, đã có một số chỉ tiêu quan trọng đạt được như giải quyết việc làm cho khoảng 31.500 lao động, đạt 100\% kế hoạch năm; Tuyển sinh mới khoảng 45.000 người, đạt $100 \%$ kế hoạch. Trong đó, các kênh giải quyết việc làm chủ yếu là phối hợp cùng Ngân hàng Chính sách xã hội, các doanh nghiệp có chức năng xuất khẩu lao động và thông qua Trung tâm giới thiệu việc làm của Thành phố. Năm 2015, đơn vị cũng đã tiếp nhận 10.775 người lao động đăng ký thất nghiệp; Thẩm định và có quyết định hưởng trợ cấp Bảo hiểm thất nghiệp cho 10.179 trường hợp.

- Về bảo hiểm xã hội, bảo hiểm y tế (BHXH, BHYT): Đối chiếu với mục tiêu Nghị quyết số 21-NQ/TW của Bộ Chính trị về tăng cường sự lãnh đạo của Đảng đối với công tác BHXH, BHYT giai đoạn 2012 - 2020, thì đến cuối năm 
2015, thành phố Đà Nẵng đã cơ bản hoàn thành vượt mức trước thời hạn chỉ tiêu về số lao động tham gia bảo hiểm thất nghiệp (có 190870 lao động tham gia bảo hiểm thất nghiệp, chiếm tỷ lệ $35.46 \%$ ) và chỉ tiêu về số người tham gia BHYT (đến cuối tháng 5-2016, thành phốĐà Nẵng có 990573 người/tổng dân số 1029000 người dân tham gia BHYT, đạt tỷ lệ 96.3\%). Có thể thấy với tỷ lệ $96.3 \%$ dân số của thành phố tham gia BHYT, dẫn đầu cả nước, là một minh chứng đầy sức thuyết phục về sự quan tâm lãnh đạo, chỉ đạo quyết liệt của Thành ủy, Hội đồng nhân dân, Ủy ban nhân dân Thành phố, sự vào cuộc cả hệ thống chính trị Thành phố, trong đó có sự đóng góp quan trọng của ngành Y tế và ngành BHXH Thành phố.

- Về công tác hỗ trợ đào tạo nghề: Không chỉ chú trọng công tác lao động việc làm, ngay từ đầu năm, Sở Lao động, Thương binh và Xã hội Thành phố đã chỉ đạo các cơ sở dạy nghề cần chủ động thực hiện các giải pháp để tuyển sinh học nghề, hướng dẫn công tác đào tạo nghề, tuyên truyền về dạy nghề miễn phí cho lao động đặc thù tại địa phương. Kết quả, trong năm 2015, toàn Thành phố đã tuyển sinh mới ước 45000 người, đạt 100.82\% so với cùng kỳ năm 2014, nâng tỉ lệ lao động qua đào tạo nghề lên 45\%;

Việc thực hiện các chính sách hỗ trợ học nghề miễn phí cho lao động đặc thù đạt được kết quả cao, theo đó Sở đã tiến hành ký kết hợp đồng với 6 cơ sở dạy nghề để tổ chức dạy nghề cho 600 lao động đặc thù trên địa bàn Thành phố, với tổng kinh phí đào tạo là 1073 triệu đồng; Tham mưu Ủy ban nhân dân Thành phố phân bổ kinh phí đào tạo nghề miễn phí cho Sở Nông nghiệp và Phát triển nông thôn, Hội nông dân, Hội Liên hiệp Phụ nữ để tổ chức dạy nghề cho 300 lao động đặc thù, với tổng kinh phí 750 triệu đồng, trong năm 2015, các cơ sở dạy nghề đã tuyển sinh đào tạo nghề cho 554 lao động đặc thù, với tổng kinh phí đào tạo là 1032 triệu đồng. Hiện nay, trên địa bàn Thành phố có 56 cơ sở dạy nghề, với quy mô đăng ký đào tạo là 50919 học viên, sinh viên của 154 nghề. Trong đó, quy mô của các cơ sở dạy nghề công lập chiếm $47.81 \%$, cơ sở dạy nghề tư thục chiếm $51.39 \%$ và cơ sở thuộc doanh nghiệp nhà nước chiếm $0.80 \%$ tổng quy mô.

- V Về chính sách đối với người có công: Hệ thống văn bản chính sách Thành phố 
ban hành dành cho người có công ngày càng hoàn thiện, toàn diện; Không bị bỏ sót, chế độ ưu đãi người có công (qua công tác rà soát hồ sơchế độ chính sách người có công năm 2014, tổng số hồ sơ người có công không sai sót chiếm 99.99\%. Các chính sách trợ cấp thường xuyên, trợ cấp 1 lần, trợ cấp đột xuất; Chính sách hỗ trợ cải thiện nhà ở, chính sách điều dưỡng nâng cao thể trạng cho đối tượng là người có công với cách mạng và các phong trào đền ơn đáp nghĩa, toàn dân chăm sóc người có công đã đem lại cho đối tượng chính sách ổn định cuộc sống và nâng mức sống lên bằng hoặc cao hơn mức sống trung bình của nhân dân nơi cư trú, trở thành trách nhiệm xã hội, tình cảm và nét văn hoá dân tộc, đạt hiệu quả kinh tế - xã hội thiết thực.

Năm 2017, Mặt trận các cấp và các tổ chức thành viên vận động đoàn viên, hội viên và nhân dân đoàn kết giúp nhau phát triển kinh tế, giúp nhau giảm nghèo bền vững, nâng cao đời sống, khuyến khích làm giàu chính đáng; Phát huy tinh thần sáng tạo và tự quản của nhân dân, tiếp tục triển khai cuộc vận động “Toàn dân đoàn kết xây dựng nông thôn mới, đô thị văn minh" gắn với thực hiện chương trình "Thành phố 4 an”; Vận động các tầng lớp nhân dân, cán bộ, đảng viên, công nhân, viên chức, lực lượng vũ trang, các tổ chức, doanh nghiệp và các nhà hảo tâm tham gia ủng hộ "Quỹ vì người nghèo", đặc biệt trong “Tháng cao điểm Vì người nghèo 2017” (từ 17/9 đến 17/10/2017); Tổ chức chương trình "Xuân yêu thương 2017” chăm lo Tết cho đồng bào nghèo.

\section{Bảng 1. Ý kiến đánh giá của người dân về hiệu quả thực thi chính sách ASXH trên địa bàn thành phố Đà Nẵng trong 5 năm gần đây (2010 - 2015)}

\begin{tabular}{lccccc}
\hline & \multicolumn{5}{c}{ Mức độ đánh giá (đơn vị tính: \%) } \\
\cline { 2 - 6 } Các chính sách & Rất tốt & Tốt & Bình thường & Không tốt Rất không tốt \\
\hline 1. Bảo trợ xã hội & 10.0 & 60.0 & 20.4 & 6.2 & 3.4 \\
2. Giảm nghèo, giải quyết việc làm, nhà ở & 7.7 & 65.8 & 21.0 & 7.1 & 0.0 \\
3. Uu đãi người có công & 5.0 & 75.0 & 20.0 & 0.0 & 0.0 \\
4. BHXH, BHYT & 2.6 & 65.0 & 25.8 & 11.0 & 0.0 \\
\hline
\end{tabular}

Nguồn: Kết quả điều tra do tác giả thực hiện

Qua đó, có thể thấy người dân thành phố Đà Nẵng đánh giá rất cao về các thành tựu của thành phố về ASXH. Có thể khẳng định rằng, về cơ bản, các chính sách ASXH 
mà lâu nay thành phố Đà Nẵng thực hiện thực sự là “cứu cánh” cho nhân dân, nhất là tầng lớp yếu thế, đang gặp phải những khó khăn, trắc trở trong cuộc sống.

\subsubsection{Nhũ̃ng hạn chế, bất cập về ASXH}

Sự phát triển kinh tế - xã hội của Thành phố đã thu hút lực lượng lớn lao động từ các tỉnh, thành phố trong cả nước tới làm việc và sinh sống, tạo áp lực lên các vấn đề ASXH. Quá trình phát triển kinh tế đã dẫn đến việc mở rộng và phát triển các ngành công nghiệp, dịch vụ đã thu hút số lượng lớn lao động từ các địa phương khác đến tham gia làm việc và cư trú, trong đó có không ít lao động tự do, những người lang thang cơ nhỡ.

- Một số vấn đề bưc xúc chậm được giải quyết: Số người trong diện yếu thế cần sự trợ giúp xã hội còn nhiều; Đời sống vật chất tinh thần chưa được nâng cao nhiều, việc làm của một bộ phận nhân dân còn khó khăn, nhất là các xã miền núi, các hộ dân thuộc diện di dời giải toả. Mức độ bao phủ một số chính sách chưa rộng khắp, khả năng tiếp cận của một số nhóm đối tượng còn hạn chế.

- Các chính sách giải quyết việc làm còn nhiều hạn chế: Mặc dù đã có những thành công nhất định trong quá trình tạo việc làm cho người lao động, song, thực tế cũng cho thấy, vấn đề giải quyết việc làm cho lao động bị thu hồi đất phục vụ phát triển công nghiệp hóa, đô thị hóa ở Đà Nẵng đang đứng trước những bất cập, khó khăn. Văn kiện Đại hội Đảng bộ thành phố Đà Nẵng lần thứ XXI cũng đã chỉ rõ việc chuyển đổi ngành nghề, giải quyết việc làm, nâng cao đời sống cho một bộ phận dân cư thuộc diện di dời giải toả thực hiện chưa tốt (Đảng bộ Đà Nẵng, 2015). Mặt khác, dưới tác động của quá trình đô thị hóa, các đối tượng dân cư bị thu hồi đất, phải chuyển đổi nghề nghiệp, phải tái định cư do quá trình mở rộng và chỉnh trang đô thị rất lớn, gây áp lực cho việc giải quyết việc làm, ổn định cuộc sống, bố trí nhà ở trên địa bàn Thành phố, gây khó khăn cho công tác ASXH.

Bên cạnh đó, hệ thống các trường đại học, cao đẳng, trung cấp đã góp phần làm tăng số lượng học sinh, sinh viên đến học tập và ở lại làm việc đã gây áp lực không nhỏ 
về vấn đề chỗ ở, khám chữa bệnh, chăm sóc y tế và các vấn đề xã hội khác (Đảng bộ Đà Nẵng, 2015). Nguyên nhân của những hạn chế, bất cập nêu trên là:

Một là, công tác tuyên truyền, phổ biến, giáo dục về nội dung và yêu cầu của chính sách ASXH có khi chưa đầy đủ, rõ ràng và kịp thời tới những đối tượng liên quan (những người thực thi và người dân), dẫn đến hiểu sai; Các văn bản hướng dẫn nhiều khi không được minh bạch, công khai;

Hai là, do tình hình suy giảm kinh tế toàn cầu, việc sản xuất, kinh doanh gặp khó khăn, đặc biệt là việc đóng băng thị trường bất động sản khiến nhiều dự án dừng, bỏ triển khai dẫn tới nguồn thu từ đất giảm mạnh - hàng loạt dự án bất động sản quy mô lớn trên địa bàn chung cảnh khó thu hồi vốn hoặc khó khăn nguồn vốn đầu tư nên chưa thể tiếp tục triển khai. Vì thế, việc trích ngân sách của thành phố và việc huy động kinh phí hỗ trợ từ các tổ chức, đơn vị, cá nhân gặp nhiều khó khăn, do đó làm hạn chế nguồn lực vận động cho công tác ASXH;

Ba là, Thành phố có nhiều dự án lớn đã và đang được triển khai, gần một trăm nghìn hộ dân đã phải di dời và cũng gần tương ứng số hộ dân được tái định cư trên địa bàn Thành phố. Tuy bộ mặt của Thành phố ngày càng khang trang, cơ sở hạ tầng được đầu tư đồng bộ và hoàn thiện hơn, bên cạnh đó cũng để lại nhiều khó khăn, nhất là việc Thành phố di dời hàng loạt các hộ dân nghèo từ nơi này sang nơi khác, đã tạo cho một số địa phương gánh nặng trong thực hiện ASXH;

Bốn là, trong những năm qua do ảnh hưởng của thiên tai (bão lũ, hạn hán, nhiễm mặn) gây ra những hậu quả nặng nề vì thế đối tượng thụ hưởng chính sách ASXH thường xuyên biến động, nhất là nhóm đối tượng yếu thế cần trợ giúp xã hội.

\subsubsection{Nhũ̃ng giải pháp đảm bảo ASXH ở Đà Nã̃ng hiện nay}

- Thứ nhất, ưu tiên phát triển đào tạo nghề, nâng cao chất lượng nguồn nhân lực đáp ứng yêu cầu phát triển kinh tế - xã hội của Thành phố;

- Thư hai, tiếp tục thực hiện có hiệu quả mục tiêu "có việc làm" trong Chương trình "3 có" của Thành phố, nhằm nâng cao chất lượng việc làm, tăng thu 
nhập cho người lao động;

- Thứ $b a$, tiếp tục duy trì mục tiêu "không có hộ đói", "không có hộ đặc biệt nghèo" theo nội dung Chương trình "thành phố 5 không" mới trên địa bàn;

- Thứ $t u$, phát triển mạnh các hoạt động ASXH; Thực hiện tốt các chính sách xã hội, vận động toàn dân tham gia các hoạt động "Đền ơn đáp nghĩa”, chăm sóc người có công với đất nước, đảm bảo đời sống ngang bằng hoặc cao hơn mức sống trung bình nơi cư trú; Đẩy mạnh các hoạt động từ thiện, nhân đạo để hỗ trợ những người yếu thế, nghèo khó trong xã hội, tạo thuận lợi cho họ tự vươn lên hoà nhập cộng đồng;

- Thú năm, thực hiện các quyền trẻ em, đảm bảo cho trẻ em có hoàn cảnh đặc biệt được bảo vệ, chăm sóc; Tạo môi trường an toàn, lành mạnh để trẻ em phát triển toàn diện; Ngăn chặn và đẩy lùi các nguy cơ xâm hại trẻ em;

- Thứ sáu, đẩy mạnh công tác phòng, chống tệ nạn xã hội, nhất là tệ nạn ma tuý; Đảm bảo người nghiện ma tuý được cai nghiện, gái mại dâm được giáo dục, chữa trị phục hồi sức khoẻ và hành vi nhân cách; Chú trọng đào tạo nghề, tạo việc làm sau cai nghiện, chữa trị, giáo dục đối với các đối tượng này.

\section{KẾT LUẬN}

Bài viết góp phần nhận thức rõ hơn quan điểm của Đảng Cộng sản Việt Nam về các chính sách $\mathrm{ASXH}$, phân tích thực trạng và định hướng một số giải pháp nhằm nâng cao vấn đề ASXH cho người dân thành phố Đà Nẵng nói riêng và ở Việt Nam nói chung.

Đảm bảo ASXH trên địa bàn Thành phố là đảm bảo các điều kiện cần thiết để thực hiện tốt chính sách $\mathrm{ASXH}$ của Nhà nước và xã hội nhằm hạn chế, phòng ngừa và khắc phục những rủi ro do những tác động khách quan đến cộng đồng dân cư trên địa bàn Thành phố, đảm bảo sự đổn định và phát triển của Thành phố. ASXH trên địa bàn Thành phố có vai trò quan trọng trong việc: Góp phần ổn định chính trị, công bằng xã hội; Đối với việc xây dựng và phát triển nguồn nhân lực cho Thành phố trong quá trình đẩy mạnh 
CNH, HĐH đất nước; Thể hiện tính nhân văn và xã hội chủ nghĩa cao cả; Tạo động lực để phát triển kinh tế và hội nhập quốc tế cho Thành phố.

Việc đảm bảo ASXH cho người dân trên địa bàn Thành phố có mối quan hệ biện chứng vừa thống nhất, vừa mâu thuẫn với phát triển kinh tế ổn định chính trị và phát triển xã hội trên địa bàn Thành phố. Vì thế, đòi hỏi việc đảm bảo ASXH trên địa bàn thành phố Đà Nẵng phải giải quyết linh hoạt, năng động và đảm bảo tính phát triển bền vững cho Thành phố trong từng giai đoạn phát triển.

\section{TÀI LIỆ THAM KHẢO}

Ban Chỉ đạo Chương trình Mục tiêu giảm nghèo. (2015). Báo cáo tổng kết tù năm 2010 đến năm 2015. Đà Nẵng, Việt Nam: NXB. Đà Nẵng.

Bộ Chính trị. (2003). Nghị quyết 33-NQ/TW về xây dưng và phát triển thành phố Đà Nã̃ng trong thời kỳ công nghiệp hóa - hiện đại hóa đất nước. Hà Nội, Việt Nam: Bộ Chính trị. Được truy lục từ http:// danang.gov.vn/chi-tiet?id=653\&_c=62.

Bộ Chính trị. (2012). Nghị quyết 21-NQ/TW về tăng cuờng sụ lãnh đạo của Đảng đối với công tác bảo hiểm xã họi, bảo hiểm y tế giai đoạn 2012 - 2020. Hà Nội, Việt Nam: Bộ Chính trị. Được truy lục từ https://thuvienphapluat.vn/van-ban/Baohiem/Nghi-quyet-21-NQ-TW-nam-2012-tang-cuong-su-lanh-dao-cua-Dangcong-tac-bao-hiem-151981.aspx.

Đảng bộ Đà Nẵng. (2015). Văn kiện Đại hội đại biểu Đảng bộ thành phố lần thứ XXI. Đà Nẵng, Việt Nam: Đảng bộ Đà Nẵng.

Đảng Cộng sản Việt Nam. (1996). Văn kiện Đại hội đại biểu toàn quốc lần thư VIII. Hà Nội, Việt Nam: NXB. Chính trị Quốc gia.

Đảng Cộng sản Việt Nam. (2001). Văn kiện Đại hội đại biểu toàn quốc lần thứ IX. Hà Nội, Việt Nam: NXB. Chính trị Quốc gia.

Đảng Cộng sản Việt Nam. (2006). Văn kiện Đại hội đại biểu toàn quốc lần thứ X. Hà Nội, Việt Nam: NXB. Chính trị Quốc gia.

Đảng Cộng sản Việt Nam. (2011). Văn kiện Đại hội đại biểu toàn quốc lần thư XI. Hà Nội, Việt Nam: NXB. Chính trị Quốc gia.

Đảng Cộng sản Việt Nam. (2016). Văn kiện Đại hội đại biểu toàn quốc lần thú XII. Hà Nội, Việt Nam: NXB. Chính trị Quốc gia.

Phùng, H. P., Nguyễn, V. Đ, \& Nguyễn, V. T. (2016). Tìm hiểu một số thuật ngũu trong Văn kiện Đại hội đại biểu toàn quốc lần thư XII của Đảng. Hà Nội, Việt Nam: NXB. Chính trị Quốc gia. 


\title{
FROM THE VIEW OF THE COMMUNIST PARTY OF VIETNAM TO THE PRACTICE OF BUILDING SOCIAL SECURITY IN DANANG
}

\author{
Le Duc Tho ${ }^{a^{*}}$ \\ ${ }^{a}$ The Faculty of Basic Subjects, Danang Vocational Training College, Danang, Vietnam \\ ${ }^{*}$ Corresponding author: Email: ductholevtc007@gmail.com \\ Article history \\ Received: August 24 $4^{\text {th }}, 2017$ \\ Received in revised form: October $03^{\text {rd }}, 2017 \mid$ Accepted: October 09 $9^{\text {th }}, 2017$

\begin{abstract}
Ensuring social security has become a central issue in national development strategies, as the care and improvement of the material and spiritual life for our people is the highest objective of the construction cause of the Socialist society in Vietnam. And now we are striving for a social security system that will cover the entire population by 2020. This article analyzes the views of the Communist Party of Vietnam on social security implementation in the current period; Analyzes the situation of social security in Danang and thereby suggests some solutions to improve social security for people in Danang city today.
\end{abstract}

Keywords: Danang; Ensure social security; Social security. 